\title{
Antiproteinuric effect of add-on paricalcitol in CKD patients under maximal tolerated inhibition of renin-angiotensin system: a prospective observational study
}

\author{
Luca De Nicola ${ }^{1,4^{*}}$, Giuseppe Conte ${ }^{1}$, Domenico Russo ${ }^{2}$, Antonio Gorini ${ }^{3}$ and Roberto Minutolo ${ }^{1}$
}

\begin{abstract}
Background: Whether paricalcitol (PCT) reduces proteinuria in the presence of intensified inhibition of Renin-Angiotensin-System (RAS) is poorly studied. We evaluated the antiproteinuric effect of PCT in non-dialysis chronic kidney disease (CKD) patients with proteinuria greater than $0.5 \mathrm{~g} / 24 \mathrm{~h}$ persisting despite anti-RAS therapy titrated to minimize proteinuria in the absence of adverse effects.

Methods: Forty-eight CKD patients were studied in the first six months of add-on oral PCT (1 mcg/day) and three months after drug withdrawal.

Results: Males were $87.5 \%$, age $63 \pm 14$ yrs, systolic/diastolic blood pressure (BP) $143 \pm 22 / 78 \pm 11 \mathrm{mmHg}$, eGFR $29.7 \pm 14.5 \mathrm{~mL} / \mathrm{min} / 1.73 \mathrm{~m}^{2}$, diabetes $40 \%$, and cardiovascular disease $38 \%$. At referral in the center (28 months prior to study baseline), proteinuria was 2.44 (95\% Cl 1.80-3.04) g/24 h with 6 patients not receiving any anti-RAS and 42 treated with a single agent, at low dosage in most cases. At study baseline, twenty patients were under 2-3 anti-RAS drugs while twenty-eight received 1 agent at full dose and proteinuria resulted to be reduced versus referral to $1.23 \mathrm{~g} / 24 \mathrm{~h}(95 \% \mathrm{Cl} 1.00-1.51)$. Six months of add-on PCT significantly decreased proteinuria to $0.61 \mathrm{~g} / 24 \mathrm{~h}$ (95\% $\mathrm{Cl}$ 0.40-0.93), with levels less than $0.5 \mathrm{~g} / 24 \mathrm{~h}$ achieved in 37.5\% patients, in the absence of changes of BP and GFR. Proteinuria recovered to basal value after drug withdrawal. The extent of antiproteinuric response to PCT was positively associated with diabetes, eGFR and daily Na excretion $\left(R^{2}=0.459, P<0.0001\right)$. PTH decreased from 201 (IQR 92-273) to 83 (IQR 50-189) pg/mL.
\end{abstract}

Conclusions: In CKD patients, add-on PCT induces a significant reduction of proteinuria that is evident despite intensified anti-RAS therapy and larger in the presence of diabetes, higher GFR and unrestricted salt intake.

Keywords: Angiotensin converting enzyme inhibitor, Angiotensin II receptor blocker, Renin inhibitor, Paricalcitol, Chronic kidney disease, Proteinuria

\section{Background}

Proteinuria is a well recognized surrogate outcome for long-term prognosis in patients with chronic kidney disease (CKD) [1]. The magnitude of proteinuria predicts in fact renal and cardiovascular (CV) events [1-3], and, more important, reduction is associated with slowing of CKD progression and CV protection $[4,5]$.

\footnotetext{
* Correspondence: luca.denicola@unina2.it

'Nephrology Departments at Second University, Napoli, Italia

${ }^{4}$ Cattedra di Nefrologia - Dip. Gerontologia, Geriatria, Mal. Metabolismo, Seconda Università di Napoli, Facoltà di Medicina, Piazza Miraglia, 80131 Napoli, Italia

Full list of author information is available at the end of the article
}

Inhibition of the renin-angiotensin system (RAS) is the cornerstone of treatment in proteinuric patients with the effect being largely independent of blood pressure (BP) control $[1,4-6]$. However, the high complexity of the system with multiple-level escape mechanisms prevents adequate suppression $[7,8]$. Indeed, monotherapy with either angiotensin converting enzyme inhibitor (ACEi) or angiotensin receptor blocker (ARB) decreases proteinuria by about 30\% [9]. Multiple blockade of RAS with either two or three drugs allows an additional decrement of proteinuria which is however still limited and heterogeneous, with many patients being left with 
significant proteinuria $[10,11]$. Therefore, novel antiproteinuric strategies aimed at attaining remission of proteinuria $(<0.5 \mathrm{~g} / 24 \mathrm{~h})$ are sought.

In the last decade, experimental evidence has been collected on an important renoprotective role of vitamin D hormone and its analogs [12,13]. Furthermore, randomized clinical trials in non-dialysis CKD have evidenced that paricalcitol (PCT), the low-calcemic vitamin D ana$\log$ currently used in Europe to prevent and treat secondary hyperparathyroidism, also acts as antiproteinuric agent when added to standard anti-RAS therapy with a single agent [14-18]. However, evidence on the antiproteinuric effect of PCT in the presence of intensified anti-RAS therapy is limited [17]. This question is critical for daily nephrology practice because intensified anti-RAS therapy, while being possibly contraindicated in patients with absent or low-degree proteinuria, is warranted in patients with proteinuric CKD treated in renal clinics $[11,19,20]$.

Aim of this study was to verify the antiproteinuric response to $\mathrm{PCT}$ in adult $\mathrm{CKD}$ patients with residual proteinuria persisting after maximal tolerated anti-RAS therapy.

\section{Methods}

This is a prospective observational study conducted in CKD patients regularly attending three nephrology outpatient clinics. The study was approved by the Institutional Review Board of the participating centers (L.D.N., G.C. and R.M.: AOU-Second University of Naples; A.G.: ASL ROMA G; D.R.: AOU-University Federico II of Naples) and all patients gave informed consent.

\section{Characteristics of centers}

The three participating centers share a protocol for management of CKD patients. Patients are always seen by the same nephrologist since the first visit in the center (referral visit). Office systolic and diastolic BP target is $<130$ and $<80 \mathrm{mmHg}$, respectively. If at referral the patient is identified as having white coat hypertension $(\mathrm{WCH})$, that is, $\mathrm{BP} \geq 130 / 80$ in office and normal $(<125 / 75 \mathrm{mmHg}) 24 \mathrm{~h}$ ambulatory BP (ABP) [21,22], office BP target is less restrictive being equal to $130 / 80 \mathrm{mmHg}$. In the three centers, ABP is performed by using Spacelabs 90207 monitors.

All patients receive personalized dietary regimens to limit dietary salt $(<6 \mathrm{~g} \mathrm{NaCl} /$ day $)$ and protein $(\leq 0.8 \mathrm{~g} / \mathrm{kg}$ body wt/day), and to avoid food and beverages containing high amounts of potassium. They also periodically undergo to serum bicarbonate testing to diagnose and treat metabolic acidosis. Compliance to drugs is evaluated at each visit in the clinic by means of specific questions on assumption of pharmacological therapy directed to the patient and family members. Specifically, physicians ask the number of times the patient had not taken the prescribed medications in the last two weeks; the patient is identified as poorly compliant to therapy, and therefore excluded from any study, if the missing rate is $\geq 20 \%$.

\section{Intensification of anti-RAS therapy}

In the three centers, anti-RAS therapy is titrated to achieve remission of proteinuria $(<0.5 \mathrm{~g} / 24 \mathrm{~h})$ in the absence of adverse effects (symptomatic hypotension or systolic blood pressure $<100 \mathrm{mmHg}$, acute eGFR decrease $>30 \%$ or serum potassium $>5.5 \mathrm{mmol} / \mathrm{L}$ ).

Participating nephrologists first administer a single anti-RAS agent (either ACEi or ARB), titrated to the full dose defined according to the manufacturer's recommendations in Italy; if proteinuria still persists above the target we combine ACEi with ARB and/or add Aliskiren (this drug is not used anymore in combination with other anti-RAS drugs according to the recommendations of the European Medicines Agency and FDA released on February and April 2012, respectively). Anti-aldosterone drugs are used as additional antiproteinuric agents only when GFR is $\geq 60 \mathrm{~mL} / \mathrm{min} / 1.73 \mathrm{~m}^{2}$. In the case of low BP levels, antihypertensive drugs other than anti-RAS are downtitrated.

\section{Selection criteria}

From September 2010 to January 2011, we selected consecutive adult CKD patients under nephrology care from at least six months in the three participating centers with eGFR $<60 \mathrm{~mL} / \mathrm{min} / 1.73 \mathrm{~m}^{2}$ (no dialysis-no transplant), proteinuria $>0.5 \mathrm{~g} / 24 \mathrm{~h}$ on two consecutive visits (30 days apart) and under intensified anti-RAS therapy unchanged from $\geq 3$ months. Exclusion criteria were steroid/ immunosuppressive treatment or eGFR change $>30 \%$ in the past 3 months, PTH levels $<20 \mathrm{pg} / \mathrm{mL}$, serum phosphorus $>5.0 \mathrm{mg} / \mathrm{dL}$, serum calcium (adjusted for albumin) $>10.0 \mathrm{mg} / \mathrm{dL}$, active malignancy.

\section{Add-on paricalcitol}

Data were collected at baseline (prior to first administration of PCT), during administration of oral PCT (after 3 and 6 months), and three months after PCT withdrawal. PCT was administered at starting dosage of $1 \mathrm{mcg} /$ day (8:00-9:00 a.m.); this dosage was chosen as it is not associated with excessive decline of parathyroid hormone (PTH) levels in most patients $[16,17]$. During the study, investigators were allowed to modify the dosage of PCT on the basis of PTH and proteinuria levels.

At each visit of the study, nephrologist performed physical examination and BP measurement. Two consecutive $24 \mathrm{~h}$-urine collection were required and results averaged. Urine collections were considered inaccurate, and repeated, if the value of measured creatinine excretion rate fell outside the normal range. Blood and urinary 
samples were analyzed by the in-hospital laboratory. GFR was estimated by the four-variable MDRD equation.

\section{Statistics}

Variables are reported as mean and standard deviation (SD) or as median and interquartile range (IQR). Proteinuria values are expressed as geometric mean and 95\% confidence interval (CI) because of their positively skewed distribution. Means are compared by paired or unpaired Student $\mathrm{t}$ test and McNemar or chi-square test for categorical variables. ANOVA for repeated measures with Bonferroni as post-hoc test are also used where appropriate. Multivariate linear regression analysis was also performed to identify the predictors of antiproteinuric response to PCT (percent change at month 6 of 24-h proteinuria from baseline). A two-tailed P-value $<0.05$ is considered significant. Data are analyzed using SPSS 12.0 (SPSS Inc, Chicago, IL, USA).

\section{Results and discussion Results}

We studied 48 Caucasian patients out of the 76 identified by inclusion criteria; twenty-eight patients were in fact excluded because of recent immunosuppressive treatment $(n=8)$, acute GFR change $(n=8)$, poor compliance to therapy $(n=7)$, low PTH $(n=5)$.

At first visit in the center (referral), performed 28 months on median (IQR 16-40) prior to add-on PCT (study baseline), patients had eGFR $38 \pm 18 \mathrm{~mL} / \mathrm{min} /$ $1.73 \mathrm{~m}^{2}$ and proteinuria $2.44(95 \% \mathrm{CI} 1.80-3.04) \mathrm{g} / 24 \mathrm{~h}$. Office BP was $148 \pm 18 / 83 \pm 13 \mathrm{mmHg}$ while $24 \mathrm{~h} \mathrm{ABP}$ was $133 \pm 17 / 76 \pm 11 \mathrm{mmHg}$, with $43 \%$ patients being identified as having $\mathrm{WCH}$. At referral, the mean number of antihypertensive drugs was $2.8 \pm 1.0$; forty-two patients were treated with a single anti-RAS drug, at low dosage in $90 \%$ cases, while the remaining six patients were anti-RAS naïve. In the first months after referral visit, four patients had been treated with immunosuppressive agents.

Table 1 shows the main basal characteristics of patients. Patients showed a high-risk profile as evidenced by the advanced age, high BMI and the large prevalence of diabetes and $\mathrm{CV}$ disease. Adherence to prescribed low salt diet ( $\mathrm{Na}$ excretion $\leq 100 \mathrm{mmol} / 24 \mathrm{~h}$ ) was low (19\%). The increase in the number of BP lowering drugs, observed at baseline versus referral visit, was mainly due to the larger use of anti-RAS agents. At baseline, in fact,

Table 1 Basal characteristics of patients, overall and by extent of proteinuria reduction after six months of paricalcitol

\begin{tabular}{|c|c|c|c|c|}
\hline & Overall & $\begin{array}{l}\text { Good Responders } \\
\text { ( } \Delta \text { Uprot } \geq 30 \%)\end{array}$ & $\begin{array}{l}\text { Poor Responders } \\
\text { ( } \Delta \text { Uprot }<30 \%)\end{array}$ & $\mathbf{P}$ \\
\hline N & 48 & 24 & 24 & \\
\hline Age (years) & $63 \pm 14$ & $64.1 \pm 11.5$ & $62.7 \pm 16.9$ & 0.735 \\
\hline Gender (M:F) & $42: 6$ & $22: 2$ & $20: 4$ & 0.666 \\
\hline Body Mass Index $\left(\mathrm{Kg} / \mathrm{m}^{2}\right)$ & $27.6 \pm 4.4$ & $27.9 \pm 3.8$ & $27.2 \pm 5.1$ & 0.593 \\
\hline Diabetes (\% pts) & 19 (39.6) & $14(58.3)$ & $5(20.8)$ & 0.017 \\
\hline Previous CV events (\% pts) & $18(37.5)$ & $11(45.8)$ & $7(29.2)$ & 0.371 \\
\hline Renal Disease (pts) & $\begin{array}{l}\text { DN (12), GN (10) } \\
\text { HN (13), APKD } \\
\text { (4) Pyelonephritis } \\
\text { (2) Nephrectomy } \\
\text { (1) Unknown (6) }\end{array}$ & $\begin{array}{l}\text { DN (9), GN (6), } \\
\text { HN (4), APKD } \\
\text { (2) Pyelonephritis } \\
\text { (1) Nephrectomy } \\
\text { (0) Unknown (2) }\end{array}$ & $\begin{array}{l}\text { DN (3), GN (4), } \\
\text { HN (9), APKD } \\
\text { (2) Pyelonephritis } \\
\text { (1) Nephrectomy } \\
\text { (1) Unknown (4) }\end{array}$ & 0.322 \\
\hline $25-\mathrm{OH}$ vitamin $\mathrm{D}(\mathrm{ng} / \mathrm{mL})$ & $18.8 \pm 10.0$ & $19.9 \pm 8.7$ & $17.6 \pm 11.2$ & 0.433 \\
\hline eGFR (mL/min/1.73 m²) & $29.7 \pm 14.5$ & $35.5 \pm 16.0$ & $23.9 \pm 10.1$ & 0.004 \\
\hline Serum albumin (g/dL) & $4.1 \pm 0.4$ & $4.0 \pm 0.5$ & $4.2 \pm 0.4$ & 0.241 \\
\hline Proteinuria (g/day) & $1.23(1.00-1.51)$ & $1.14(0.81-1.61)$ & $1.32(1.02-1.71)$ & 0.501 \\
\hline UNaV (mEq/day) & $161 \pm 63$ & $183 \pm 60$ & $141 \pm 52$ & 0.012 \\
\hline Systolic BP (mmHg) & $143 \pm 22$ & $146 \pm 19$ & $141 \pm 24$ & 0.453 \\
\hline Diastolic BP (mmHg) & $78 \pm 11$ & $78 \pm 11$ & $78 \pm 12$ & 0.980 \\
\hline Antihypertensive Drugs ( $n$ ) & $3.6 \pm 1.4$ & $3.3 \pm 1.4$ & $3.8 \pm 1.4$ & 0.224 \\
\hline Anti-RAS per patient (n) & $1.6 \pm 0.7$ & $1.5 \pm 0.7$ & $1.6 \pm 0.8$ & 0.848 \\
\hline Furosemide (\%) & $24(50.0)$ & $14(58.3)$ & $10(41.7)$ & 0.387 \\
\hline Furosemide dose $(\mathrm{mg} / \mathrm{d})$ & $63 \pm 30$ & $60 \pm 32$ & $64 \pm 31$ & 0.742 \\
\hline CCB (\%) & $25(52.1)$ & $13(54.2)$ & $12(50.0)$ & 1.00 \\
\hline Beta Blocker (\%) & $27(56.3)$ & $17(70.8)$ & $10(41.7)$ & 0.080 \\
\hline
\end{tabular}

Data are mean \pm SD or percentage or geometric mean and (95\% confidence interval). CV, cardiovascular; DN, diabetic nephropathy; GN, glomerulonephritis; HN, hypertensive nephropathy; APKD, autosomal polycystic kidney disease; eGFR, 4-variable MDRD estimated GFR; BP, blood pressure; RAS, renin angiotensin system; CCB Calcium Channel Blocker. 
twenty patients were under multiple blockade of RAS; they received either ACEi + ARB $(n=11)$ or ARB + Aliskiren $(n=1)$ or $A C E i$ + Aliskiren $(n=1)$ or $A C E i+A R B+$ Aliskiren $(n=7)$. Intensification of anti-RAS therapy was also obtained in the twenty-eight patients administered a single anti-RAS agent; at referral, in fact, these drugs were not used in four or used at low dosage in the remaining twenty-four patients while at baseline all patients were treated with anti-RAS at full dose. In these 28 patients, combined therapy was considered unfeasible because, during the previous follow up in the center, adding the second anti-RAS agent had been associated with documented acute GFR decline $(\mathrm{n}=8)$, hypotension $(\mathrm{n}=7)$, hyperkalemia $(n=13)$. As compared with patients under combined anti-RAS therapy, those receiving anti-RAS monotherapy were older ( $69 \pm 11$ vs $55 \pm 14$ years) and had lower levels of eGFR $(26 \pm 12$ vs $35 \pm 17 \mathrm{~mL} / \mathrm{min} /$ 1.73) $(\mathrm{P}<0.05$ for both).

As reported in Table 2, add-on PCT was associated with a progressive decline in PTH levels that, however, did not decrease below the lower limit of normal range $(20 \mathrm{pg} / \mathrm{mL})$ in any patient. No significant change of alkaline phosphatase (ALP) levels was observed, with only two patients at month 3 and one patient at month 6 showing ALP levels below the lower limit of normal range (40 IU/L). Serum calcium and phosphate remained within normal range in all patients but one that had a single episode of hyperphosphatemia $(6.4 \mathrm{mg} / \mathrm{dL})$ at month 3 due to excessive phosphorus intake. In this patient, PCT was temporarily withdrawn and re-started at $1 \mathrm{mcg} /$ day within one month after successfully reinforcing dietary advices and administering a phosphate binder. Binders were constantly administered throughout follow up in seven patients.

Add-on PCT induced a progressive decrease of proteinuria (Table 2). Remission of proteinuria to values $<0.5 \mathrm{~g} / 24 \mathrm{~h}$ was achieved in $14.6 \%$ at month 3 , and in $37.5 \%$ by month $6(\mathrm{P}=0.007$ vs month 3$)$. These results were obtained in the presence of an unchanged antihypertensive therapy (mean number from baseline to month 6 was $3.6 \pm 1.4,3.6 \pm 1.4$ and $3.4 \pm 1.4$, respectively) and a small reduction in the number of anti-RAS $(1.6 \pm 0.7,1.4 \pm 0.8$ and $1.4 \pm 0.8$, respectively). The median reduction of proteinuria after six months of PCT was $32 \%$ (IQR 11-52). No correlation was found between percentual change in proteinuria and systolic BP $(\mathrm{r}=0.146, \mathrm{P}=0.324)$.

Table 1 reports the basal characteristics of good and poor responders to PCT, as defined according to the extent of proteinuria reduction around the median value ( $\geq 30 \%$ and $<30 \%$, respectively). Median reduction of proteinuria was $57 \%$ (IQR: 46-72) in good responders and $11 \%$ (from -8 to 22 ) in poor responders. Good responders showed greater prevalence of diabetes, and higher eGFR and $24 \mathrm{~h}$ urinary sodium excretion. Multiple linear regression analysis of antiproteinuric response as continuous variable (model summary: $\mathrm{R}^{2}=0.459, \mathrm{P}<0.0001$ ) confirmed the greater antiproteinuric effect in the presence of diabetes $(P=0.022)$, higher eGFR $(P=0.004)$ and higher daily $\mathrm{Na}$ excretion $(\mathrm{P}=0.005)$ while association with age and gender was not significant.

The first dose of PCT $(1 \mathrm{mcg} /$ day $)$ did not change throughout the six months of follow up in 40/48 patients, halved in three patients (low PTH or gastrointestinal intolerance), and doubled in five (increasing PTH and/or proteinuria).

To verify the dependence of proteinuria reduction on $\mathrm{PCT}$, we evaluated the change of proteinuria three months after drug withdrawal. This analysis was not possible in six patients because, after month 6 , three of them started hemodialysis, two had a flare of underlying glomerulonephritis that required immunosuppressive therapy, and one moved to other town. In the 42 patients undergoing PCT withdrawal, proteinuria recovered to baseline (Figure 1). In these patients, median PTH was 206 (102270) $\mathrm{pg} / \mathrm{mL}$ at baseline, $90(51-188) \mathrm{pg} / \mathrm{mL}$ at month 6

Table 2 Changes of main parameters during Paricalcitol (PCT) in the whole cohort $(n=48)$ and three months after withdrawal $(n=42)$

\begin{tabular}{lllll}
\hline & Basal & Month $\mathbf{3}$ & Month 6 & PCT withdrawal \\
\hline SBP/DBP $(\mathrm{mmHg})$ & $143 \pm 22 / 78 \pm 11$ & $137 \pm 15 / 78 \pm 10$ & $138 \pm 17 / 79 \pm 10$ & $134 \pm 16 / 77 \pm 9$ \\
\hline eGFR $\left(\mathrm{mL} / \mathrm{min} / 1.73 \mathrm{~m}^{2}\right)$ & $29.7 \pm 14.5$ & $27.3 \pm 15.5$ & $27.5 \pm 16.2$ & $26.9 \pm 15.3$ \\
\hline Serum potassium $(\mathrm{mmol} / \mathrm{L})$ & $4.6 \pm 0.7$ & $4.8 \pm 0.7$ & $4.8 \pm 0.6$ & $4.7 \pm 0.6$ \\
\hline PTH $(\mathrm{pg} / \mathrm{mL})$ & $201(92-273)$ & $140(64-226)^{*}$ & $83(50-189)^{*}$ & $111(74-184)^{*}$ \\
\hline ALP $(\mathrm{IU} / \mathrm{L})$ & $155 \pm 96$ & $148 \pm 86$ & $143 \pm 93$ & $135 \pm 95$ \\
\hline Serum Calcium $(\mathrm{mg} / \mathrm{dL})$ & $9.3 \pm 0.6$ & $9.3 \pm 0.5$ & $9.4 \pm 0.4$ & $9.3 \pm 0.6$ \\
\hline Serum Phosphate $(\mathrm{mg} / \mathrm{dL})$ & $3.9 \pm 0.7$ & $3.9 \pm 0.8$ & $3.9 \pm 0.7$ & $3.9 \pm 0.7$ \\
\hline Proteinuria $(\mathrm{g} / 24 \mathrm{~h})$ & $1.23(1.00-1.51)$ & $0.85(0.59-1.21)^{*}$ & $0.61(0.40-0.93)^{*}$ & $1.12(0.86-1.44)$ \\
\hline UNaV $(\mathrm{mmol} / 24 \mathrm{~h})$ & $161 \pm 63$ & $144 \pm 55$ & $149 \pm 65$ & $157 \pm 66$ \\
\hline
\end{tabular}

Data are mean \pm SD or median and interquartile range (PTH) or geometric mean and 95\% confidence interval (proteinuria). SBP/DBP, systolic/diastolic blood pressure; eGFR, 4-variable MDRD estimated GFR; ALP, Alkaline Phosphatase; UNaV, 24 h urinary Na excretion. ${ }^{*} \mathrm{P}<0.05$ vs basal. 


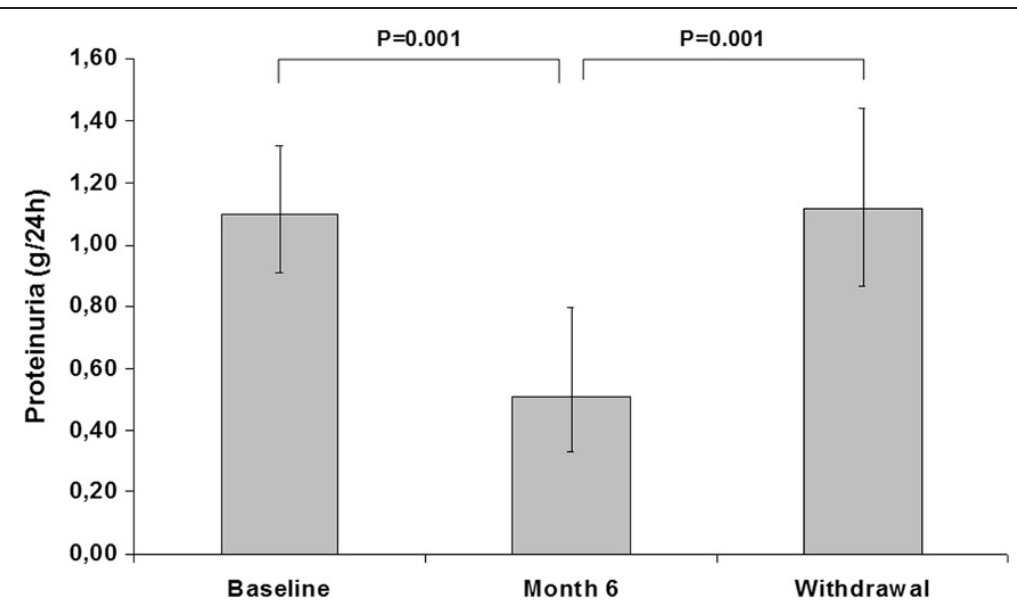

Figure 1 Proteinuria levels measured in 42 patients before (baseline), after add-on Paracalcitol (Month 6), and after three-month drug withdrawal. Data are geometric mean and $95 \%$ confidence interval. See text (Results) for missing patients.

and $111(74-184) \mathrm{pg} / \mathrm{mL}$ after withdrawal $(\mathrm{P}<0.05$ for month 6 and withdrawal versus baseline).

\section{Discussion}

The co-existence of proteinuria $>0.5 \mathrm{~g} / 24 \mathrm{~h}$ and GFR $<60 \mathrm{~mL} / \mathrm{min} / 1.73 \mathrm{~m}^{2}$ identifies a subgroup of CKD patients which carries the highest cardio-renal risk [1-3]. In these patients, minimizing RAS activity is a main target of treatment $[1,3,6]$. Such a subgroup of CKD patients was the object of the current study. Enrolled subjects were in fact encumbered by multiple risk factors and significant proteinuria despite intensified anti-RAS treatment. This therapeutic feature represents the main difference with the previous studies on antiproteinuric effect of PCT where patients did not consistently undergo intensification of anti-RAS therapy prior to add-on PCT [14-17]. In our cohort, the preliminary intensification of anti-RAS therapy during the interval between referral and study baseline (two years on median) is testified by the marked decrease of proteinuria in the absence of major changes of antihypertensive therapy other than anti-RAS. As a consequence of the predominant use of anti-RAS versus other drugs, only a mild decline of BP values from the referral visit was observed. The large prevalence of $\mathrm{WCH}(43 \%)$, that is expected in tertiary nephrology care [23], further restrained participating nephrologists from intensifying antihypertensive agents other than anti-RAS. Of note, in this observational study in outpatient clinics, we enrolled patients under maximal tolerated anti-RAS therapy. In this regard, it is noteworthy that patients treated with a single anti-RAS, that were older and with more advanced CKD, had documented side effects when implementation of combined treatment was attempted. Under the peculiar condition of intensified anti-RAS therapy, add-on PCT induced a $32 \%$ reduction of proteinuria, with a substantial portion of patients (38\%) showing remission of proteinuria $(<0.5 \mathrm{~g} / 24 \mathrm{~h})$.

Assessment of underlying pathophysiological mechanisms goes beyond the original purpose of the study. We hypothesize that the additive antiproteinuric effect of PCT may be at least in part related to more effective RAS inhibition. Indeed, experimental data converge to indicate that PCT blunts the compensatory increase of renin synthesis secondary to the disruption of the feedback inhibition loop occurring during chronic administration of anti-RAS agents $[12,13,24]$. Therefore, the detrimental effects on the kidney of renin, that can occur also independently from AII [7], may be limited in the course of add-on PCT therapy. Nevertheless, antiinflammatory effects, direct and indirect (mediated by suppression of intrarenal RAS activity), as well as lessening of podocyte injury, cannot be excluded $[12,13,25,26]$.

The extent of antiproteinuric effect of PCT was greater in the presence of higher GFR, diabetes and higher salt intake (Table 1). These associations persisted when considering the proteinuria change as continuous variable in the multiple regression analysis adjusted for age and gender. The influence of GFR is expected, being conceivably related to the amount of irreversible proteinuria that increases in parallel with advancing nephrosclerosis [2]. Therefore, in the specific context of this study including patients with GFR $<60$, the more is preserved renal function the greater is the reduction of proteinuria. In this regard, recent studies have disclosed that also less expensive interventions such as nutritional vitamin $\mathrm{D}$ repletion or administration of calcitriol, that is a less potent and more calcemic vitamin D analog [27], reduce proteinuria in patients with milder degrees of renal disease, such as microalbuminuric diabetic nephropathy with moderate GFR impairment and IgA nephropathy with close-to-normal GFR [28,29]. 
Of greater interest is the larger antiproteinuric effect of PCT evidenced in diabetics; the higher response may be related to the greater activity of intrarenal RAS $[30,31]$, and/or to the specific positive effects of PCT on glomerular barrier [26]. Interestingly, recent studies have also evidenced an association between decrements of albuminuria and urinary TGF- $\beta$ in type 2 diabetics treated with cholecalciferol [28].

On the other hand, more puzzling is the positive relationship between antiproteinuric response and salt intake. Indeed, it is well known that high salt intake blunts the beneficial effects of anti-RAS therapy [32,33]. As in the current study, also the VITAL trial showed enhanced antiproteinuric effect of add-on PCT in diabetic CKD patients under standard anti-RAS therapy when salt intake was high [17]. We obtained similar data when we evaluated the antiproteinuric effect of aliskiren given on the top of dual RAS blockade [11]. On this basis, we can therefore hypothesize that the greater antiproteinuric effect of PCT in patients at higher sodium intake could be explained by the suboptimal antiproteinuric efficacy of anti-RAS under these conditions. Conversely, when patients adhere to sodium restriction, the antiproteinuric response to anti-RAS is already elevated and the antiproteinuric effect of add-on PCT is therefore limited. Independent of underlying mechanism, the finding is of great clinical interest as the majority of patients are not compliant to salt restriction even if followed in renal clinics [2].

The significant antiproteinuric effect of PCT was not impaired by major adverse effects, thus extending to this subgroup of high-risk and poly-treated patients the favorable safety profile of PCT previously reported [13-18]. PTH and ALP remained in the normal range in most patients. This finding supports the experimental evidence that low-dose PCT, given in the absence of exogenous calcium loading, is not associated to excessive suppression of bone turnover [34].

Interpretation of results is limited by the small sample size and the absence of control group; nevertheless, the remarkable antiproteinuric response and the recovery of proteinuria to baseline after three months of drug withdrawal support the validity of our observations. As regard the recovery of proteinuria after drug withdrawal, however, we cannot exclude some degree of escape of proteinuria which is a not a uncommon finding when inhibition of RAS is intensified $(7,8,11)$. Furthermore, more prolonged follow up is required to verify efficacy and safety of this approach over the long-term. Finally, we did not assess systemic RAS activity. While it precludes from gaining insights into the mechanism(s) of the antiproteinuric effects of add-on PCT, the antihypertensive poly-therapy and the outpatient setting of the study, with the consequent uncontrolled external balance of sodium, prevent any meaningful evaluation of this system in our patients. However, it is well known that intrarenal rather than systemic RAS acts as the major control mechanism $[7,8]$.

\section{Conclusions}

This study suggests that in patients with low GFR and persisting proteinuria despite maximal tolerated anti-RAS therapy: (1) add-on PCT safely allows a reduction of proteinuria with a remarkable achievement of levels $<0.5 \mathrm{~g} /$ $24 \mathrm{~h}$ in more than one-third of cases, (2) antiproteinuric response to PCT is greater in diabetics, patients with higher GFR and in the presence of unrestricted salt intake.

PCT therefore represents a potential additional therapeutic option to be considered when intensified antiRAS treatment is not completely efficacious or unfeasible because of adverse effects. Whether the antiproteinuric effect of PCT translates into improvement of prognosis of these high-risk patients is worth investigating.

\section{Abbreviations \\ ABP: 24 h Ambulatory blood pressure; ACEi: Angiotensin converting enzyme inhibitor; ALP: Alkaline phosphatase; ARB: Angiotensin receptor blocker; BMI: Body mass index; BP: Blood pressure; CKD: Chronic kidney disease; CV: Cardiovascular; eGFR: Estimated glomerular filtration rate; IQR: Interquartile range; MDRD: Modification of diet in renal disease; PCT: Paricalcitol; PTH: Parathyroid hormone; RAS: Renin-Angiotensin-System; SD: Standard deviation; VITAL: Selective vitamin D receptor activator for Albuminuria lowering; WCH: White coat hypertension.}

\section{Competing interests}

There is no conflict of interest on this work

\section{Authors' contributions}

LDN and RM had full access to all the data in the study and takes responsibility for the integrity of the data and the accuracy of the data analysis. All Authors gave the final approval of the submitted version of the paper. Study concept and design: LDN, RM. Acquisition of data: LDN, GC, AG, RM, DR. Analysis and interpretation of data: LDN, RM. Drafting of the manuscript: LDN. Critical revision of the manuscript: GC, AG, RM, DR. Study supervision: LDN, GC, AG, RM, DR. All authors read and approved the final manuscript.

\section{Authors' information}

LDN: Associate Professor of Nephrology, Second University of Naples, Italy. GC: Full Professor of Nephrology, Second University of Naples, Italy. DR: Associate Professor of Nephrology, University Federico II of Naples, Italy. AG: Consultant Nephrologist, Nephrology and Dialysis Unit, S. Giovanni Evangelista Hospital, Tivoli, Italy.

RM: Aggregate Professor of Nephrology, Second University of Naples, Italy. All Authors are members of the Italian Society of Nephrology.

\section{Transparency declarations}

L.D.N. has received consulting fee from Amgen and Roche and honoraria for lectures for Abbott, Amgen, Roche.

G. C. has received honoraria for lectures for Amgen, Roche.

D.R. received honoraria for lectures for Roche, Abbott, Genzyme, Amgen. A.G. has received consulting fee from Abbott.

R.M. has received consulting fee from Roche and honoraria for lectures for Abbott, Amgen, Roche.

\section{Acknowledgements}

The results presented in this paper have not been published previously except as abstract(XLVIII ERA-EDTA Congress in Prague, Czech Republic, June 23-26, 2011. 


\section{Author details}

${ }^{1}$ Nephrology Departments at Second University, Napoli, Italia. ${ }^{2}$ University Federico II, Napoli, Italia. ${ }^{3}$ S. Giovanni Evangelista Hospital, Tivoli, Italy. ${ }^{4}$ Cattedra di Nefrologia - Dip. Gerontologia, Geriatria, Mal. Metabolismo, Seconda Università di Napoli, Facoltà di Medicina, Piazza Miraglia, 80131 Napoli, Italia.

Received: 16 July 2012 Accepted: 18 November 2012

Published: 20 November 2012

\section{References}

1. Levey AS, Cattran D, Friedman A, Miller WG, Sedor J, Tuttle K, Kasiske B, Hostetter T: Proteinuria as a surrogate outcome in CKD: report of a scientific workshop sponsored by the National Kidney Foundation and the US Food and Drug Administration. Am J Kidney Dis 2009, 54:205-226.

2. De Nicola L, Chiodini P, Zoccali C, Borrelli S, Cianciaruso B, Di lorio B, Santoro D, Giancaspro V, Abaterusso C, Gallo C, Conte G, Minutolo R, SIN-TABLE CKD Study Group: Prognosis of CKD patients receiving outpatient nephrology care in Italy. Clin J Am Soc Nephrol 2011, 6:2421-2428.

3. Ruggenenti P, Perna A, Remuzzi G, GISEN Group Investigators: Retarding progression of chronic renal disease: the neglected issue of residual proteinuria. Kidney Int 2003, 63:2254-2261.

4. de Zeeuw D, Remuzzi G, Parving HH, Keane WF, Zhang Z, Shahinfar S, Snapinn S, Cooper ME, Mitch WE, Brenner BM: Albuminuria, a therapeutic target for cardiovascular protection in type 2 diabetic patients with nephropathy. Circulation 2004, 110:921-927.

5. Eijkelkamp WB, Zhang Z, Remuzzi G, Parving HH, Cooper ME, Keane WF, Shahinfar S, Gleim GW, Weir MR, Brenner BM, de Zeeuw D: Albuminuria is a target for renoprotective therapy independent from blood pressure in patients with type 2 diabetic nephropathy: post hoc analysis from the Reduction of Endpoints in NIDDM with the Angiotensin II Antagonist Losartan (RENAAL) trial. J Am Soc Nephrol 2007, 18:1540-1546.

6. K/DOQI clinical practice guidelines on hypertension and antihypertensive agents in chronic kidney disease. Am J Kidney Dis 2004 43:S1-\$230.

7. Müller DN, Luft FC: Direct renin inhibition with aliskiren in hypertension and target organ damage. Clin J Am Soc Nephrol 2006, 1:221-228.

8. Velez JC: The importance of the intrarenal renin-angiotensin system. Nat Clin Pract Nephrol 2009, 5:89-100

9. Wolf G, Ritz E: Combination therapy with ACE inhibitors and angiotensin II receptor blockers to halt progression of chronic disease: pathophysiology and indications. Kidney Int 2005, 67:799-812.

10. Kunz R, Friedrich C, Wolbers M, Mann JF: Metaanalysis: effect of monotherapy and combination therapy with inhibitors of the reninangiotensin system on proteinuria in renal disease. Ann Intern Med 2008 148:30-48.

11. De Nicola L, Zamboli P, Bellizzi V, Stanzione G, Russo D, Nappi F, Minco M, Chiodini P, Conte G, Minutolo R: Antiproteinuric response to add-on aliskiren in proteinuric patients treated with dual blockade of the reninangiotensin system: a 12-month prospective uncontrolled study. Am J Kidney Dis 2011, 57:961-963.

12. Li YC: Renoprotective effects of vitamin D analogs. Kidney Int 2010, 78:134-139

13. Agarwal R: Are vitamin D receptor agonists like angiotensin-converting enzyme inhibitors without side effects? Kidney Int 2010, 77:943-945.

14. Agarwal R, Acharya M, Tian J, Hippensteel RL, Melnick JZ, Qiu P, Williams L, Batlle D: Antiproteinuric effect of oral paricalcitol in chronic kidney disease. Kidney Int 2005, 68:2823-2828.

15. Alborzi P, Patel NA, Peterson C, Bills JE, Bekele DM, Bunaye Z, Light RP, Agarwal R: Paricalcitol reduces albuminuria and inflammation in chronic kidney disease: a randomized double-blind pilot trial. Hypertension 2008, 52:211-212.

16. Fishbane $\mathrm{S}$, Chittineni $\mathrm{H}$, Packman M, Dutka P, Ali N, Durie N: Oral paricalcitol in the treatment of patients with CKD and proteinuria: a randomized trial. Am J KidneyDis 2009, 54:647-652.

17. de Zeeuw D, Agarwal R, Amdahl M, Audhya P, Coyne D, Garimella T, Parving $H H$, Pritchett $Y$, Remuzzi G, Ritz E, Andress D: Selective vitamin D receptor activation with paricalcitol for reduction of albuminuria in patients with type 2 diabetes (VITAL study): a randomised controlled trial. Lancet 2010, 376:1543-1551.
18. Cheng J, Zhang W, Zhang X, Li X, Chen J: Efficacy and safety of paricalcitol therapy for chronic kidney disease: a meta-analysis. Clin J Am Soc Nephrol 2012, 7:391-400.

19. Bianchi S, Bigazzi R, Campese VM: Intensive versus conventional therapy to slow the progression of idiopathic glomerular diseases. Am J Kidney Dis 2010, 55:671-681.

20. Ruggenenti P, Perticucci E, Cravedi P, Gambara V, Costantini M, Sharma SK, Perna A, Remuzzi G: Role of remission clinics in the longitudinal treatment of CKD. J Am Soc Nephrol 2008, 19:1213-1224.

21. O'Brien E, Asmar R, Beilin L, Imai Y, Mallion JM, Mancia G, Mengden T, Myers M, Padfield P, Palatini P, Parati G, Pickering T, Redon J, Staessen J, Stergiou G, Verdecchia P: European Society of Hypertension Working Group on Blood Pressure Monitoring: European Society of Hypertension recommendations for conventional, ambulatory and home blood pressure measurement. J Hypertens 2003, 21:821-848.

22. Kikuya M, Hansen TW, Thijs L, Björklund-Bodegård K, Kuznetsova T, Ohkubo T, Richart T, Torp-Pedersen C, Lind L, Ibsen H, Imai Y, Staessen JA: International Database on Ambulatory blood pressure monitoring in relation to Cardiovascular Outcomes (IDACO) Investigators: diagnostic thresholds for ambulatory blood pressure monitoring based on 10-year cardiovascular risk. Circulation 2007, 115:2145-2152.

23. Minutolo R, Borrelli S, Scigliano R, Bellizzi V, Chiodini P, Cianciaruso B, Nappi F, Zamboli P, Conte G, De Nicola L: Prevalence and clinical correlates of white coat hypertension in chronic kidney disease. Nephrol Dial Transplant 2007, 22:2217-2223.

24. Zhang Z, Zhang Y, Ning G, Deb DK, Kong J, Li YC: Combination therapy with AT1 blocker and vitamin D analog markedly ameliorates diabetic nephropathy: blockade of compensatory renin increase. Proc Natl Acad Sci USA 2008, 105:15896-15901.

25. Tan $X$, Wen $X$, Liu Y: Paricalcitol inhibits renal inflammation by promoting vitamin $D$ receptor-mediated sequestration of NF-kappaB signaling. J Am Soc Nephrol 2008, 19:1741-1752.

26. Deb DK, Sun T, Wong KE, Ning G, Zhang Y, Kong J, Shi H, Chang A, Li YC: Combined vitamin $D$ analog and AT1 receptor antagonist synergistically block the development of kidney disease in a model of type 2 diabetes. Kidney Int 2010, 77:1000-1009.

27. Sprague SM, Llach F, Amdahl M, Taccetta C, Batlle D: Paricalcitol versus calcitriol in the treatment of secondary hyperparathyroidism. Kidney Int 2003, 63:1483-1490.

28. Kim MJ, Frankel AH, Donaldson M, et al: Oral cholecalciferol decreases albuminuria and urinary TGF- $\beta 1$ in patients with type 2 diabetic nephropathy on established renin-angiotensin-aldosterone system inhibition. Kidney Int 2011, 80:851-860.

29. Liu LJ, Lv JC, Shi SF, Chen YQ, Zhang H, Wang HY: Oral calcitriol for reduction of proteinuria in patients with IgA nephropathy: a randomized controlled trial. Am J Kidney Dis 2012, 59:67-74.

30. Burns KD: Angiotensin II, and its receptors in the diabetic kidney. Am J Kidney Dis 2000, 36:449-467.

31. Huang XR, Chen WY, Truong LD, Lan HY: Chymase is upregulated in diabetic nephropathy: implications for an alternative pathway of angiotensin II-mediated diabetic renal and vascular disease. J Am Soc Nephrol 2003, 14:1738-1747.

32. De Nicola L, Minutolo R, Bellizzi V, Zoccali C, Cianciaruso B, Andreucci VE, Fuiano G, Conte G: Achievement of target blood pressure levels in chronic kidney disease: a salty question? Am J Kidney Dis 2004 43:782-795

33. Cianciaruso B, Bellizzi V, Minutolo R, Tavera A, Capuano A, Conte G, De Nicola L: Salt intake and renal outcome in patients with progressive renal disease. Miner Electrolyte Metab 1998, 24:296-301.

34. Slatopolsky E, Cozzolino M, Lu Y, Finch J, Dusso A, Staniforth M, Wein Y, Webster J: Efficacy of 19-Nor-1,25-(OH)2D2 in the prevention and treatment of hyperparathyroid bone disease in experimental uremia. Kidney Int 2003, 63:2020-2027.

doi:10.1186/1471-2369-13-150

Cite this article as: De Nicola et al: Antiproteinuric effect of add-on paricalcitol in CKD patients under maximal tolerated inhibition of reninangiotensin system: a prospective observational study. BMC Nephrology 2012 13:150 